\title{
Model tests and numerical analyses on the mechanism of flow-out of railway ballasts induced by flood inundation
}

\author{
K. Hayano \\ Professor, Yokohama National University, 79-5, Tokiwadai, Hodogaya, Yokohama, 240-0065, Japan.
}

\begin{abstract}
Recently in Japan, railway ballasts have been flown out several times by heavy or intense rainfalls. However, the mechanism has not yet been investigated in detail, so that the risk and the countermeasures cannot be reasonably proposed. Therefore, in this research, model tests and numerical analyses were conducted to investigate the flow-out mechanism. It was found that the seepage characteristics of ballast beds can be expressed based on Forchheimer law not on Darcy law. Progressive failures were observed in the model tests. It was also found that the stability of the ballast beds can be reasonably explained by the proposed micro-mechanic approach.
\end{abstract}

Keywords: heavy rainfall, inundation, railway ballast, flow-out, micro-mechanic model

\section{INTRODUCTION}

Recently in Japan, railway ballasts have been flown out several times by heavy or intense rainfalls. It has been reported that the flow-out of ballasts can frequently accompany the outflow of railway tracks (Tsubaki et al. 2011, Ueda et al. 2012). However, the flow-out mechanism has not yet been investigated in detail, so that the risk and the countermeasures cannot be reasonably proposed. Therefore, in this research, model tests and numerical analyses were conducted to investigate the flow-out mechanism.

\section{MODEL TEST APPARATUS AND CONDITIONS}

Railway ballasts which were crushed andesite taken in Yamanashi Prefecture in Japan were used for model tests. An outline of the model test apparatus used in this study is shown in Fig. 1. The apparatus was consisted of three components as listed below.

1. Water flow circulation system consisting of two water channels and several hydraulic pumps.

2. Ballast beds constructed in a water channel as shown in Fig. 2.

3. Data acquisition system by which water pressures and deformations of ballast beds were measured.

The model tests were conducted four times, which were named as case A through $\mathrm{D}$. The size of ballast bed constructed for each test is shown in Table 1. All the ballast beds were compacted to achieve the dry density $1.60 \mathrm{~g} / \mathrm{cm}^{3}$. After construction of the ballast beds, water flows were given to them as follows.
First, a constant volume of water flow was given to a ballast bed with the water flow circulation system. After the steady state flow was achieved, upstream and downstream side water levels of the ballast bed were measured as well as pore water pressures inside the bed. Change of slope shape of the bed was also measured at the downstream side. After all the data were acquired, the water flow rate was stepwise increased up to predetermined levels. At each flow rate level, the data acquirements were repeated.

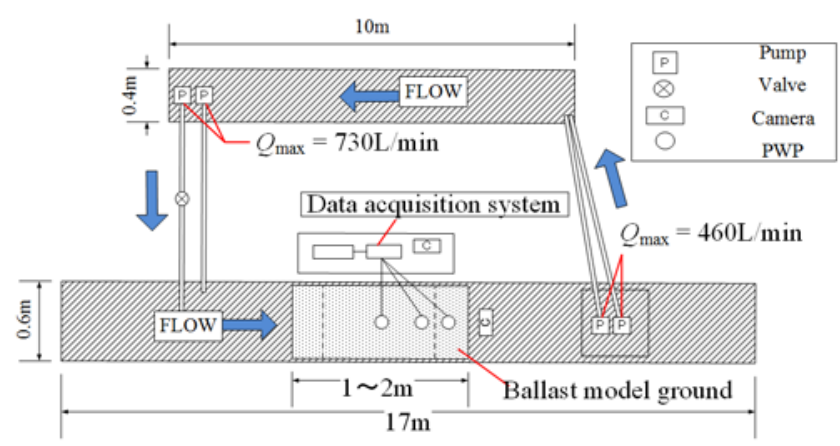

Fig. 1. Plan view of model test apparatus.

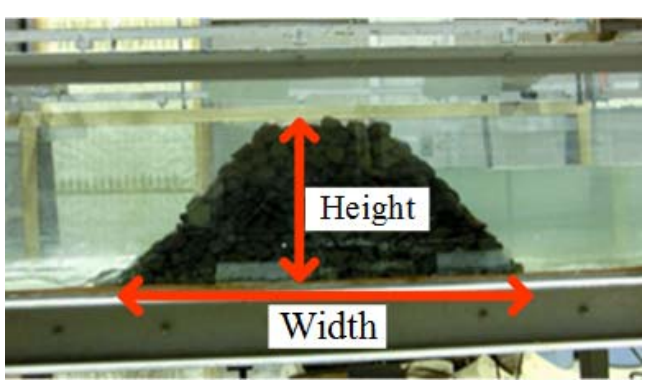

Fig. 2. Ballast bed in a water channel (case A). 
Table 1. Model test conditions.

\begin{tabular}{|c|c|c|c|c|c|c|}
\hline & Width & Height & Length & Dry density & Porosity & Slope angle \\
\hline caseA & $1.00 \mathrm{~m}$ & $0.39 \mathrm{~m}$ & & & & \\
\cline { 1 - 1 } caseB & $1.20 \mathrm{~m}$ & \multirow{2}{*}{$0.25 \mathrm{~m}$} & $0.6 \mathrm{~m}$ & $1.60 \mathrm{~g} / \mathrm{cm}^{3}$ & 0.41 & $45^{\circ} \quad(1: 1)$ \\
\cline { 1 - 2 } caseC & & & & & & \\
\hline caseD & $2.00 \mathrm{~m}$ & & &
\end{tabular}

*) Case C was conducted to investigate the reproducibility of case $\mathrm{B}$ results.

\section{MODEL TEST RESULTS}

\subsection{Seepage characteristics}

Fig. 3 shows the relationships between the flow rate per unit length $q$ and the upstream side water level $h_{\text {in }}$ as well as the downstream side water level $h_{\text {out }}$. As shown in the figure, with the increase of $q, h_{\text {in }}$ became higher. This trend was more significantly observed in case $\mathrm{D}$, simply because the seepage distance was longer and the overall hydraulic gradient was lower owing to the wider bed. The increase rate of $h_{\text {in }}$ significantly became lower in all cases except for case A, when overflows were observed. Overflow was not observed in case A because the ballast bed was higher compared to others. Looking into the relationships between $q$ and $h_{\text {out, }}$ it was found that the difference among the test cases was small.

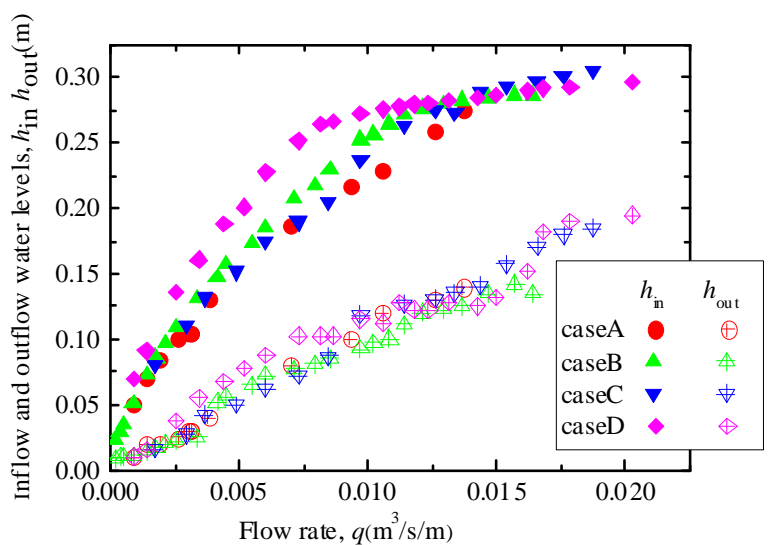

Fig. 3. Upstream and downstream water levels against flow rates.

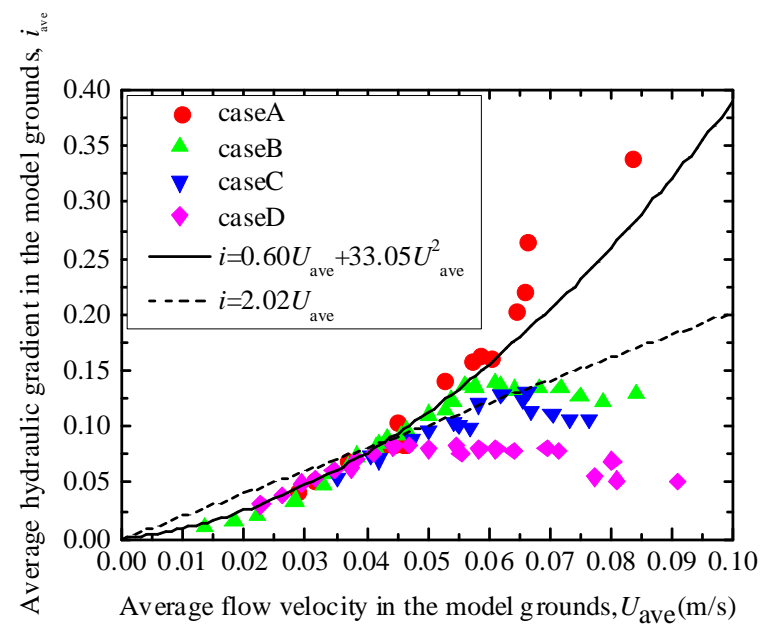

Fig. 4. Average hydraulic gradients against average flow velocities.
Based on the relationships shown in Fig. 3, average velocities $U_{\text {ave }}$ and average hydraulic gradients $i_{\text {ave }}$ were estimated by the following equations.

$$
\begin{gathered}
U_{\text {ave }}=\frac{2 q}{h_{\text {in }}+h_{\text {out }}} \\
i_{\text {ave }}=\frac{h_{\text {in }}-h_{\text {out }}}{L-1 / 2\left(h_{\text {in }}+h_{\text {out }}\right)}
\end{gathered}
$$

where, $L$ is the ballast bed width.

As shown in Fig. 4, the relationships $U_{\text {ave }}-i_{\text {ave }}$ were not linear so that they could not be represented by the Darcy law. The relationships were well represented by the Forchheimer law which estimates the hydraulic gradient by the sum of velocity and its square. Similar trend was reported in Holloway, 2001, in which column tests were conducted on ballasts to evaluate the permeability characteristics.

The increase of $i_{\text {ave }}$ with increase of $U_{\text {ave }}$ was observed in all cases, but $i_{\text {ave }}$ did not increase further after overflows occurred in cases B through D. The difference of the $U_{\text {ave }}-i_{\text {ave }}$ relationships were very small among the test cases until the overflows occurred. This limited portion was fitted by the equation $i_{\text {ave }}=$ $a U_{\text {ave }}+b U^{2}$ ave as shown in the figure. Consequently, $a$ and $b$ were obtained as 0.60 and 33.05 , respectively.

\subsection{Progressive failure}

Slope shapes of the ballast bed at the downstream side in case D is shown in Fig. 5. The slope shape was gradually changed with the increase of the flow rate $q$. First, a few number of ballasts were slipped-out from the bed (STEP1). Then, a small slope collapse occurred (STEP2). The collapse deposited several ballasts near the slope toe. The deposited ballasts were washed out with the increase of the flow rate, resulting in appearance of a steep slope (STEP3). Subsequently, a large slope collapse occurred because of the lack of overall stability (STEP4). Thus, progressive slope failures starting from the slip-out of ballasts were found. They were also observed in other test cases.

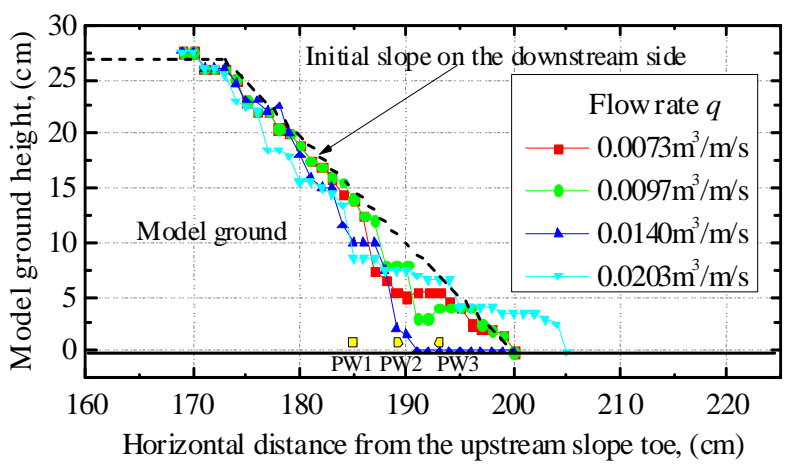

Fig. 5. Change of slope surface profiles with the increase of flow rate (case $\mathrm{D}$ ). 


\subsection{Slip-out of ballasts}

Detailed investigation was conducted on the slip-out of ballasts which triggered the progressive slope failures. Three pore water pressure gauges PW1 through 3 were set near the slope toe at the downstream side as shown in Fig. 5 to measure pore water pressures. Based on the measurements, pore fluid velocities $U_{\text {local }}$ pore and hydraulic gradients $i_{\text {local }}$ near the slope toe were estimated by the following equations.

$$
\begin{gathered}
U_{\text {local }}^{\text {pore }}=\frac{2 q}{n\left(h_{i}+h_{i+1}\right)} \\
i_{\text {local }}=\frac{h^{p}{ }_{i}-h^{p}{ }_{i+1}}{L_{p}}
\end{gathered}
$$

Here $h^{\mathrm{p}}$ is the piezometric head, $h$ is the water level at the water pressure gauge installation position, and $L_{\mathrm{p}}$ is the distance between the pressure gauges. Subscripts $i$ refer to numbers 1,2 and 3 of the pressure gauge.

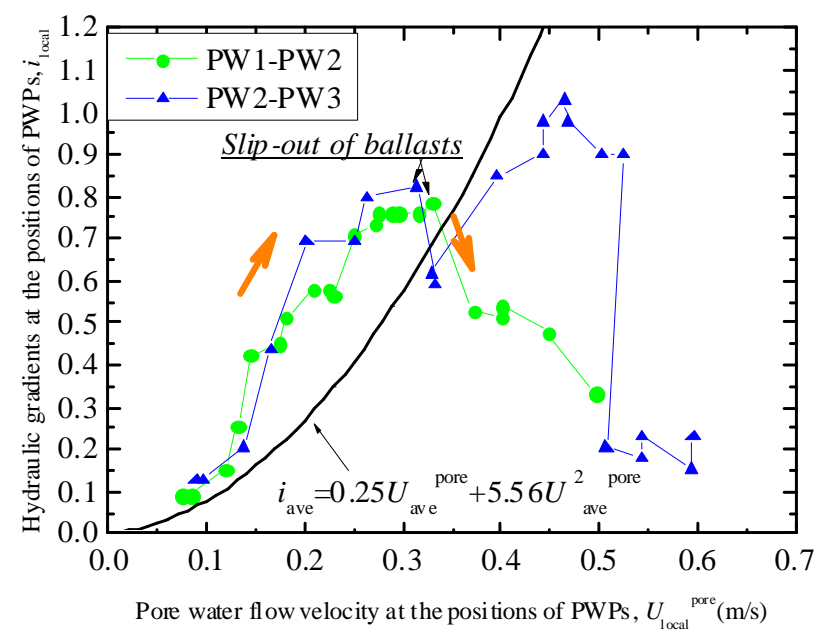

Fig. 6. Local hydraulic gradient against pore water flow velocity near the downstream slope toe (Case D).

Fig. 6 shows the relationships between $U_{\text {local }}$ pore and $i_{\text {local }}$ obtained from case $\mathrm{D}$. The relationship $i_{\text {ave }}=a U_{\text {ave }}$ pore $+b U_{\text {ave }}^{2}$ pore converted from the equation $i_{\text {ave }}=a U_{\text {ave }}+$ $b U_{\text {ave }}^{2}$ shown in Fig.4 with using the relation $U_{\text {ave }}^{\text {pore }}=U_{\text {ave }} / n$ are also plotted in the figure. Here $n$ is the porosity (see Table 1 ). By this conversion, $a$ and $b$ became 0.25 and 5.56, respectively.

It is found that the relationships between $U_{\text {local }}{ }^{\text {pore }}$ and $i_{\text {local }}$ are also nonlinear and show the same trend as that expressed by the equation $i_{\text {ave }}=a U_{\text {ave }}^{\text {pore }}+b U_{\text {ave }}^{2}$ pore . Rapid reduction of $i_{\text {local }}$ observed in the figure represents that the permeability of the ballast bed suddenly became higher, indicating the occurrence of the slip-out of ballasts.

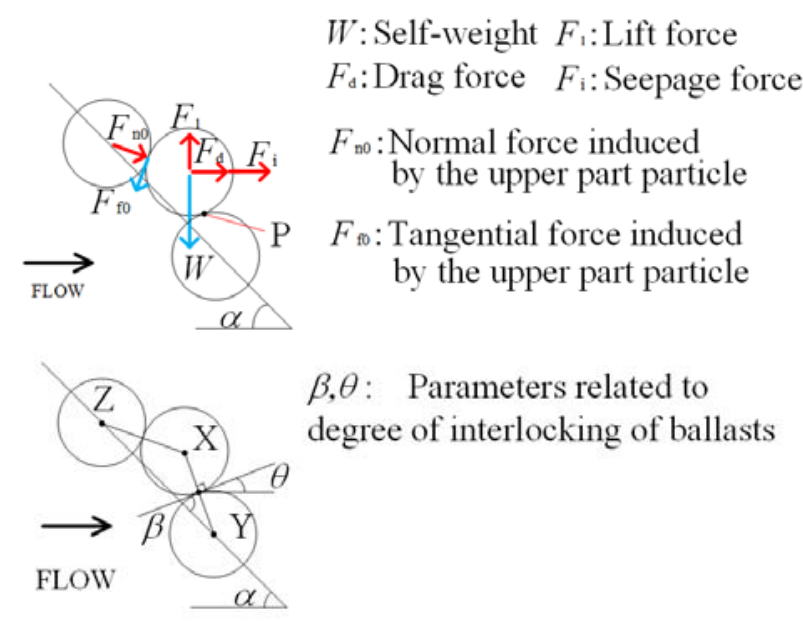

Parameter values in this study $\beta=\left(\beta_{\max }+\beta_{\min }\right) / 2=\left(90^{\circ}+45^{\circ}\right) / 2=67.5^{\circ}$

$\theta$ can be determined in consideration of $\alpha=45^{\circ}$

Fig. 7. Micro model to evaluate the stability of a ballast particle at the downstream slope.

\section{MICRO-MECHANIC MODEL FOR THE SLIP-OUT OF BALLASTS}

Michioku et al. 2014 estimated stabilities of rubble-mound weirs based on the equilibrium of forces acting on rubbles which were assumed to have a circular particle shape. On the basis of this idea, analyses were attempted to investigate the slip-out stability of ballast beds.

Fig. 7 shows circular shape ballast particles $\mathrm{X}$ through $\mathrm{Z}$ along the downstream side slope and the forces acting on the particle X. The slope angle $\alpha$ in the present study was 45 degrees (see Table 1 ). The safety factor $F_{\mathrm{s}}$ for the rotation of the particle $\mathrm{X}$ with respect to a point $\mathrm{P}$ can be estimated by the following equation.

$$
F_{s}=\frac{W \sin \theta+F_{f 0}\left\{1+\sin \left(2 \beta-90^{\circ}\right)\right\}}{F_{d} \cos \beta+F_{l} \sin \beta+F_{i} \cos \beta+F_{n 0} \sin \left(90^{\circ}-\beta\right)}
$$

Definition of each force is shown in Fig. 7. The forces in the figure were calculated by the following equations.

$$
\begin{gathered}
F_{d}=1 / 2 \varepsilon C_{d} A U_{\text {ave }}^{2 \text { pore }} \\
F_{l}=1 / 2 \varepsilon C_{l} A U_{\text {ave }}^{2 \text { pore }} \\
F_{i}=i_{\text {ave }} \rho_{w} g V=\left(a U_{\text {ave }}^{\text {pore }}+b U_{\text {ave }}^{2 \text { pore }}\right) \rho_{w} g V
\end{gathered}
$$




$$
\begin{gathered}
F_{n 0}=\rho_{s} g V \cos \left(180^{\circ}-\alpha-\beta\right) \\
(180-\alpha-\beta>90 \text { degrees }) \\
F_{f 0}=\mu F_{n 0}
\end{gathered}
$$

The circular particle area, $V$ was obtained by the following equation.

$$
V=\pi d^{2} / 4
$$

The parameters except for $\theta$ and $\beta$ in the above equations were determined based on Michioku et al. 2014 or from the model test conditions. They were shown in Table 2.

Table 2. Input parameters

\begin{tabular}{|l|l||l|l|}
\hline Shield coefficient, $\varepsilon$ & 1.0 & Particle density, $\rho_{\mathrm{s}}$ & $2.71 \mathrm{~g} / \mathrm{cm}^{3}$ \\
\hline Drag coefficient, $C_{\mathrm{d}}$ & 0.5 & Water density, $\rho_{\mathrm{w}}$ & $1.00 \mathrm{~g} / \mathrm{cm}^{3}$ \\
\hline Lift coefficient, $C_{\mathrm{l}}$ & 0.5 & $\begin{array}{l}\text { Friction coefficient } \\
\text { between particles, } \mu\end{array}$ & 0.5 \\
\hline Projected area, $A$ & $\pi d$ & Particle diameter, $d$ & $3.5 \mathrm{~cm}$ \\
\hline
\end{tabular}

The parameters $\theta$ and $\beta$ represent the degree of interlocking between ballast particles as shown in Fig.7. Here $\theta$ could be obtained from the slope inclination angle $\alpha$ and $\beta$. Because the information has not been well provided related to, $\beta$ was set to be 67.5 degrees, which is just an intermediate value between the weakest state and the strongest state as shown in Fig. 8.

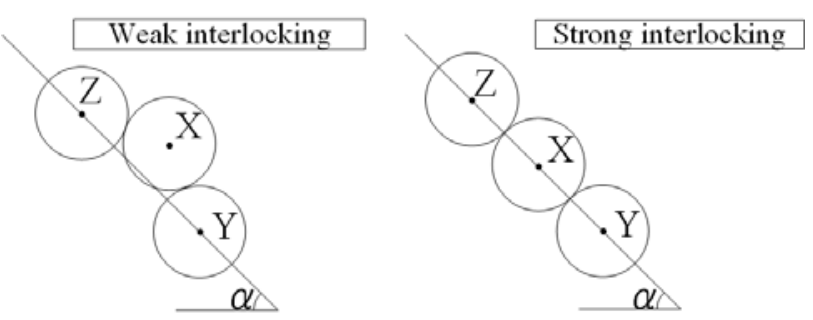

Fig. 8. Assumption for the degree of interlocking states at the slope.

With using the Eqs. (5) through (11), the velocities $U_{\text {ave }}$ pore where the safety factor $F_{\mathrm{s}}$ became 1.0 or less were estimated. The range of $U_{\text {ave }}{ }^{\text {pore }}$ are plotted on the relationship $i_{\text {ave }}=0.25 U_{\text {ave }}^{\text {pore }}+5.56 U_{\text {ave }}^{2}$ pore in Fig. 9. As seen in the figure, the velocities $U_{\text {local }}$ pore when the slip-outs were observed in the experiments are very close to $U_{\text {ave }}{ }^{\text {pore }}$ where $F_{\mathrm{s}}$ became 1.0. The fact indicates that the slip-out timing can be reasonably explained by the micro-mechanic approach.

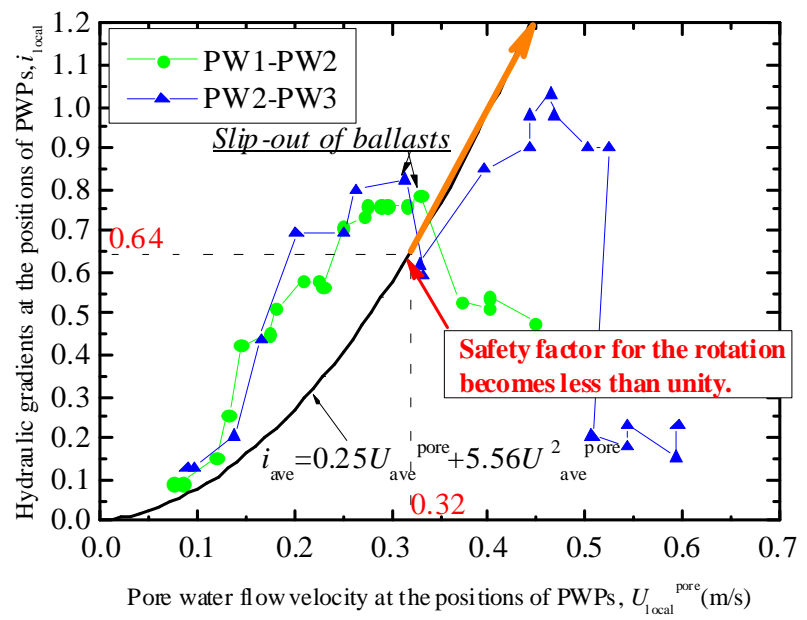

Fig. 9. Hydraulic gradient and pore water flow velocity which gives the unstable state for the particle in the micro-mechanic model.

\section{CONCLUSIONS}

In this study, model tests were conducted to investigate railway ballast flow-out mechanisms when heavy or intense rainfalls occur. As the results, the following findings were obtained.

1) Permeability characteristics of the ballast beds are well understood by the Forchheimer law rather than Darcy law.

2) The ballast beds collapse progressively, which are triggered by the slip-out of a few numbers of ballasts at the downstream side slope.

3) The comparison between the model test results and the analytical results indicate that the flow velocity required for the slip-out can be reasonably explained by the proposed micro-mechanic approach.

\section{REFERENCES}

1) Holloway, D. S. (2001): Estimation of stormwater flow through railway ballast, Proceedings of $6^{\text {th }}$ conference on Hydraulics in Civil engineering: 289-297.

2) Michioku, K., Ishigaki, T., Maeno, S., Takehara, K., Etoh, T., Nanjo, M. and Haneda, M. (2004): Hydrodynamic properties of rubble mound weir and groin installed in an open channel, Annuals of Disas. Prev. Res. Inst., Kyoto Univ., No.47 B.

3) Tsubaki, R., Kawahara, Y. and Ueda, Y. (2011): Experimental study on railway embankment breach, Advances in River Engineering 17: 449-454 (in Japanese).

4) Ueda, Y., Tsubaki, R., Kawahara, Y. and Yoshida, K. (2012): Experimental study on process and criteria of railway ballast breaching, Advances in River Engineering 18: 375-380 (in Japanese). 